II. Aus der II. medicinischen Klinik des Herrn Geh. Rath Prof. Dr. Gerhardt in Berlin.

\title{
Ueber die Anämieen bei Lungentuberculose
} und Carcinose. $\left.{ }^{1}\right)$

Von Dr. E. Grawitz,

Stabsarzt und Privatdocenten, Assistenten der Klinik.

Die Zeichen der Anämie gehören bei Kranken, welche an Lungentuberkulose oder Carcinom leiden, zu den gewöhnlichsten Erscheinungen und stehen sogar in vielen Fällen derart im Vordergrunde, dass sie in Verbindung mit der häufig vorhandenen Abmagerung den Kranken eine gewisse Aehnlichkeit verleihen, infolge deren beide Leiden im Volksmunde nicht selten unter dem Namen der Abzehrung zusammengeworfen werden.

Diese beiden Krankheiten nun, welche in der Mehrzahl der Fälle chronisch mit allmählich zunehmender Kachexie verlaufen, zeigen bei gleich stark ausgeprägter Blässe der Haut eine derartige Verschiedenheit ihrer Anämie - d. h. Verschlechterung der Blutbeschaffenheit ganz im allgemeinen -, dass es gerade wegen der Häufigkeit derselben angebracht erscheint, durch sorgfältige Untersuchungen des Blutes nach verschiedenen Richtungen hin das Wesen und die Aetiologie dieser Anämieen zu studiren.

Die Litteratur über derartige Blutuntersuchungen ist recht zahlreich, und die hauptsächlichsten Arbeiten sind z. B. in Reiner't's Buch über die Blutzählungen und vor kurzem bei v. Noorden in seinem Lehrbuch der Pathologie des Stoffwechsels zusammengestellt. Eine genaue Angabe der Litteratur bringt Herr Dr. Stra u er auf meine Veranlassung in einer Dissertation, welche die detaillirten Befunde unserer gemeinsam angestellten Blutanalysen enthält. ${ }^{2}$ )

Ich will hier nur kurz bemerken, dass bisher die meisten Untersuchungen nach ein er Richtung hin angestellt sind, also sich entweder mit der Frmittelung des Hämoglobingehaltes, oder der Zahl der Blutkörperchen, oder der Blutdichte, oder der Trockenrückstände des Blutes bei diesen Krankheiten beschäftigen.

Aus diesen Untersuchungen geht hervor, dass bei Tuberkulose im allgemeinen die Verminderung der normalen Theile des Blutes nieht besonders stark zu sein pflegt, sobald nicht Blutverluste, Eiterungen und andere Complicationen eintreten, dass dagegen bei Carcinose stets eine beträchtliche Verschlechterung der Blutzusammensetzung zu beobachten ist.

Auf Grund vieler früherer Erfahrungen erschien es mir nothwendig, um ein wirklich klares Bild der Veränderungen des Blutes zu bekommen, die Untersuchungen möglichst vielseitig auszuführen, und wir haben infolgedessen gleichzeitig bestimmt:

1. Die Zahl der rothen Blutkörperchen;

2. Die Zahl der weissen Blutkörperchen;

3. Den Trockenrückstand des Blutes;

4. Den Trockenrückstand des Blutserum;

5. Das specifische Gewicht des Blutes.

Diese verschiedenen Bestimmungen wurden in der Erwägung ausgeführt, dass die Zahlen der rothen und weissen Blutzellen an sich keinen absoluten Aufschluss über die Qualität des Gesammtblutes geben, da der Eiweiss- und speciell der Hämoglobingehalt desselben durchaus nicht immer diesen Zahlen proportional ist.

Aber auch der Trockenrückstand des Blutes giebt an sich über den Hämoglobingehalt noch keinen sicheren Anhalt, da der letztere z. B. durchaus normal sein kann, wenn auch die Durchschnittsziffer des Trockenrückstandes nicht erreicht wird, da diese Erniedrigung der Ziffer durch eine Herabsetzung allein des Serums an festen Bestandtheilen bedingt sein kann. Infolgedessen wurde der Trockenrückentand auch vom Serum isolirt bestimmt, zu welchem Zwecke dasselbe nach 24 stündigem Stehen von einer zweiten Blutprobe mit einer feinen Pipette abgehoben wurde.

Die Bestimmung des specifischen Gewichtes habe ich einer Reihe von Untersuchungen angefügt, um mich über das Verhalten desselben gegenüber den anderen Untersuchungsresultaten zu orientiren, und ich erwähne gleich hier, dass das specifische Gewicht in manchen Fällen nicht nur zu der Zahl der rothen Blutkörperchen, sondeln auch zu dem Trockenrückstande in einem gewissen Missverhältnisse stand, sodass sich die Werthe dieser Bestimmungen unter einander nicht immer deekten.

Die Entnahme des Blutes, von dem für die verschiedenen Bestimmungen im ganzen etwa $1,5-2 \mathrm{~g}$ nöthig waren, habe ich in einheitlicher Weise aus dem venösen System bewerkstelligt, und zwar durch Punction einer der oberflächlichen Armvenen mittels einer feinen Hohlnadel, wie dies durch v. Ziemssen bereits vor lăngerer Zeit zu intravenösen Injectionen

1) Nack einem im Verein für innere Medicin gehaltenen Vortrage.

2) Strauer, Systematische Blutuntersuchungen bei Schwindsuichtigen und Krebskranken. Greifswald, 1893. 
empfohlen worden ist, wobei gleichzeitig darauf geachtet,wurde, dass weder durch $\mathrm{zu}$ reichliches noch $\mathrm{zu}$ spärliches Trinken vor der Untersuchung eine Beeinflussung der Blutconcentration stattfand.

Die Wichtigkeit einer einheitlichen Blutentnahme, die meines Erachtens durch Stiche oder Schnitte in die Haut nie so exact gleichmässig ausgeführt werden kann, wie bei der direkten Entnahme aus einem Gefässe, ist häufig genug betont worden, die Belästigung der Kranken ist bei der Venenpunction erheblich geringer, als beim Anlegen eines Schnittes in die Fingerkuppe oder Ohrzipfel, irgend eine Schädignng der Kranken ist niemals zu beobachten gewesen.

Wenn man bei dieser Art der Blutentnahme einwenden wollte, dass das venöse Blut gewisse Veränderungen dem übrigen Blute gegenüber zeigt, so muss ich zunächst hervorheben, dass das sogenannte Capillarblut, welches man durch einen Stich in die Haut erhält, niemals wirklich reines Capillarblut sein kann, da immer eine Anzahl von Lymphspalten durch die Verletzung der Haut mitgeöffnet wird, und eine mehr oder minder starke Verdünnung des Blutes durch Lymphe eintreten muss, eine Fehlerquelle, die besonders dann ganz erheblich und uncontrollirbar wird, wenn man sich zur Gewinnung grösserer Mengen von Blut der Aspiration durch Aufsetzung von Schröpfköpfen bedient, da hier bei Anwendung grösserer oder geringerer Luftverdünnung, bei Vorhandensein stärkerer Füllung der Hautcapillaren, bei verschiedener Straffheit der Haut und mehreren anderen variablen Factoren ganz verschiedene Blutconcentrationen bei einem und demselben Individuum in mehreren entnommenen Proben erhalten werden.

Da nun arterielles Blut für diese Untersuchungen beim Menschen nicht in Frage kommt, so gewinnt man in dem Blute, welches schnell und ohne Stauung oder Aspiration aus der Vene in die breitgehaltenen Gefässe tropft, jedenfalls ein ganz unverändertes Blut, bei welchem man auch ein Verdunsten infolge langsamen Ausflusses nicht zu besorgen hat.

Die Zahlen selbst, welche man bei vergleichenden Untersuchungen, wie den vorliegenden, erhalt, sind weniger durch ihre absolute Höhe wichtig, sondern vorwiegend relativ durch die Vergleichung mit einander, es ist mithin weniger wichtig, aus welchem Bezirk das Blut stammt, als dass es in allen Fällen in einheitlicher Weise, unverändert entnommen und einheitlich mit zweifellosen Methoden untersuchtwird. Inbezug auf diesen letzteren Punkt bemerke ich, dass die Trockenrückstände ausnahmslos im Vacumm über Schwefelsäure gewonnen wurden, nachdem das Blut in hermetisch schliessenden Wiegeschälchen aufgefangen und auf Zehntelmilligramme abgewogen war.

Dass man die Trockenrückstände des Blutes nur auf diese Weise, die ich seit langem übe und die meines Erachtens durchaus nicht besonders umständlich ist, wirklich exact bestimmen kann, hat auch $\nabla$. Jaksch auf dem letzten Congress für innere Medicin betont.

Die Durchschnittswerthe, welche ich hierbei für Gesunde orhielt, betrugen 21,50 Trockenrü ckstand für das Blut und $10,75 \%$ für das Serum.

Auf die Technik der Zählungen und Gewichtsbestimmungen brauche ich nicht näher einzugehen, die letzteren geschahen im Pyknometer.

\section{A. Blut bei Tuberkulösen.}

Eine Uebersicht über 32 genaue Blutanalysen bei Tuberkulösen, die sich in den verschiedensten Stadien der Erkrankung befanden, ergiebt zunächst anf den ersten Blick ein sehr buntes Bild. Die Zahlen differiren bei den einzelnen Patienten sehr erheblich, so dass sich sogleich ergiebt, dass man nicht vom Blute von Tuberkulösen schlechthin sprechen kann, sondern die einzelnen Gruppen gesondert betrachten muss.

Wenn ich zunächst alle Complicationen der chronischen Lungentuberkulose ausser acht lasse, so treten drei Phasen der Blutbeschaffenheit hervor, welche sich deutlich von einander scheiden lassen.

In der ersten Phase findet man in der Regel im Blute die ausgesprochenen Zeichen der Anämie, nämlich eine Herabsetzung der Zahl der Blutkörperchen, die der weissen Blutkörperchen unregelmässig, die Trockensubstanz des Blutes und des Serum herabgesetzt, ebenso das specifische Gewicht des Blutes.

Diese Phase findet sich als Regel bei beginnender Spitzenaffection, wenn noch keine Cavernensymptome vorhanden sind, und steht meist durchaus in Uebereinstimmung mit der schon an der äusseren Haut wahrnehmbaren Blässe, ohne dass dabei eine nennenswerthe Abmagerung zu bestehen braucht. Fin mittelwerthiges Beispiel liefert die 24 jährige W., die vor zwei Jahren einmal Bluthusten, später trocknen Husten gehabt. Dieselbe ist blass, zeigt eine Schallabschwächmng iiber der einen
Lıngenspitze mit vereinzelten Rasselgeräıschen. Sputum nicht producirt, kein Fieber, keine Schweisse.

Das Blut enthält: 4,2 Millionen rothe, 6000 weisse Blutkörperchen.
Gesammttrockensubstanz
des Serums . $\begin{gathered}18,66 \% \\ 9,70 \%\end{gathered}$
Specifisches "Gewicht
1050,0 .

Bei kräftigen Personen ohne äussere Blässe findet man in diesem Stadium der Lungentuberkulose normale Werthe.

Die zweite Gruppe bilden sodann alle die Schwindsüchtigen, deren Krankheit chronisch ohne besondere Complicationen mit der Bildung von Cavernen verläuft, und bei denen Fieber gar nicht oder nur in geringem Grade besteht.

Alle diese Kranken, welche fast ausnahmslos hochgradige Blässe der Hant und mehr oder weniger starke Abmagerung zeigen, bieten nun den auffälligsten Befund dar, indem ihre Blutbeschaffenheit nur wenig, oft überhaupt gar nicht von der normalen $\mathrm{Zu}$ sammensetzung abweicht.

Die Zahl der rothen Blutkörperchen ist mit geringen Schwankungen annähernd normal, manchmal sogar in der Raumeinheit vermehrt, die der weissen meist zwischen 5- und 10000 im Cubikmillimeter. Die Trockensubstanz des Blutes, wie auch des Serums kann bei völlig normalen Zahlen der Blutkörperchen etwas vermindert sein, häufig zeigt aber auch sie die normalen Durchschnittswerthe, ja noch darüber hinaus. Das spezifische Gewicht ist meist etwas höher, als es dem Gehalt an Trockensubstanz entspricht. Ein Beispiel ans dieser Gruppe zeigt folgende Zahlen:

S., 20 jähriger, kräftig gebauter Mann mit Cavernensymptomen iiber der linken Lungenspitze, Tuberkelbacillen im Auswurf, sehr blass, fieberfrei, ohne Schweisse.

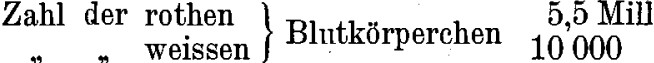

$$
\begin{aligned}
& \text { Trockensubstanz des Blutes } \quad 10000 \\
& \text { Specifisches Gewicht Serums. . . } 9,40 \text { " } 1053,0
\end{aligned}
$$

Als dritte $\mathrm{Phase}$ sind sodann die Stadien zu bezeichnen, in welchen sich zu der Lungentuberkulose stärkere remittirende oder intermittirende Fieber hinzugesellen, und zwar besonders jene Fieber, die man seit alters als hektische bezeichnet, und von denen man neuerdings annehmen $\mathrm{zu}$ müssen glaubt, dass sie unabhängig von den eigentlichen tuberknlösen Zerstörungen durch die Fiebererreger in den Cavernen hervorgerufen werden, wohingegen leichte Fieberbewegungen, wie sie auch bei Kranken der zweiten Gruppe zum Theil vorhanden waren, nach Strümpell's') Auffassung, der ich mich durchaus anschliesse, durch den tuberkulösen Process allein ohne Secundärinfection hervorgerufen werden können.

In diesen Stadien trifft man stets eine allgemeine Verschlechterung der Blutmischung an, die rothen Blıtkörperchen sind stark vermindert, die weissen häufig vermehrt, die Trockensubstanz des Blutes und des Serums sind herabgesetzt, und dementsprechend ist das specifische Gewicht gesunken. Alle diese Werthe gehen meist progressiv mit der Dauer des Fiebers herunter und können sub finem vitae öfters sehr geringe Zahlen aufweisen, falls nicht besondere Complicationen eine Eindickung des Blutes bewirken.

Es zeigte Th., 20jähriges Mädchen, mit Infiltration beider Lungenspitzen, Tuberkelbacillen im Sputum und starker Blässe, anfänglich fast ganz fieberfrei:

Zahl der rothen Blutkörperchen

Zahl der weissen Blutkörperchen

4,25 Millionen

Trockensubstanz des Blutes

2500

Trockensubstanz des Serums

und nach achttägigem hohem Fieber:

Zahl der rothen Blutkörperchen

Zahl der weissen Blutkörperchen

Trockensubstanz des Blutes

Trockensubstanz des Serums

$20,80 \%$

$10,28 \%$

3,00 Millionen

6000

$19,70 \%$

$10,07 \%$

Noch stärkere Veränderungen als diese letzte Phase im Verlaufe der chronischen Lungentuberkulose bietet das Blut bei den acuten Formen, die mit hohem Fieber und schnellem Zerfall des Lungengewebes einhergehen und eine Herabsetzung aller der erwähnten Zahlen und Werthe, manchmal bis zu ganz abnorm niedrigen Ziffern aufweisen

So zeigte z. B. die 34 jährige Patientin D., an florider Lungentuberkulose mit hohem Fieber bei starken Remissionen leidend: rothe Blutkörperchen

weisse Blutkörperchen

Trockensubstanz des Blutes

Trockensubstanz des Serums

specifisches Gewicht

0,7 Millionen

6000

$14,43 \%$

$6,84 \%$

1032,0 .

Gesondert von allen diesen Gruppen müssen endlich die Blut-

9) Münch. med. Wochenschr. 1892, p. 50, 51. 
befunde bei den Schwindsüchtigen mit Complicationen behandelt werden, von denen ich hier folgende erwähnen will.

Häinoptoë bedingt je nach dem Grade ihrer Stärke eine Herabsetzung der Zahl der rothen Blutkörperchen und Verminderung der Trockensubstanz des Blutes und des Serums. Kehlkopftuberkulose kann bei.Stenosenbildung zur Eindickung des Blutes infolge von Stauung im venösen Gebiete führen und daher die erwähnten Werthe erhöhen.

Bei amyloider Degeneration innerer Organe scheint immer Verschlechterung der Blutmischung einzutreten.

Bei Complication mit Diabetes mellitus constatirten wir Eindickung des Blutes.

Kurz zusammengefasst zeigt sich also bei chronischer Lungentuberkulose im ersten Beginn der Erkrankung im BIute eine Verminderung der rothen Blutkörperchen und der Trockensubstanz, im zweiten Stadium dagegen, trotz bestehender hochgradiger Blässe und Abmagerung, trotz nachweisbarer Cavernen annähernd normale, manchmal übernormale Zahlen der rothen Blutkörperchen mit normalen, in einigen Fällen mässig herabgesetzten Werthen für die Trockensubstanz. Bei vorgeschrittener Phthise, zu der sich Fieber stärkeren Grades hinzugesellt hat, ganz besonders bei den acuten Formen entzündlicher Lungentuberkulose, finden sich für alle erwähnten $\mathrm{Be}$ standtheile des Blutes niedrige Werthe.

Diese Verhältnisse der Blutmischung, welche in Hinsicht auf die normalen Werthe im zweiten Stadium durchaus paradox erscheinen, in ihrer Aetiologie klarzulegen, soll der Zweck der folgenden Zeilen sein.

Ganz naturgemäss erscheint zunächst die Verminderung der rothen Blutkörperchen und der Trockensubstanz im Beginne der Erkrankung, wobei auch die Haut und Schleimhäute die Zeichen der Anämie darbieten, sei es, dass dieselbe durch die beginnende Tuberkulose selbst oder durch schlechte Ernährung hervorgerufen sei. Wie aber erklärt sich der annähernd normale Blutbefund im weiteren Verlaufe der Krankheit, wenn die Blässe und Abmagerung noch stärker hervorgetreten sind, und siclı ein ulceröser Zerfall in den Lungen deutlich nachweisen lässt. Der Widerspruch zwischen diesen Blutbefunden und der allgemein gültigen Anschauung, dass Phthisis in der Regel mit starker Anämie verbunden ist, hat Laache ${ }^{1}$ ) zu der Anschauung geführt, „dass Phthisis an und für sich in den meisten Fällen keine Veranlassung zu bedeutender Anämie giebt". Ich führe diese Interpretation der Blutbefunde, auf welche ich weiter unten noch zurückkommen werde, hier nur an, um zu zeigen, wie auffällig diese Blutbefunde auch anderen schon erschienen sind.

Die nächstliegende Erklärung ist die, dass durch profuse Secretionen, ganz besonders des Schweisses, in manchen Fällen des Bronchialsecretes oder diarrhoischer Entleerungen das Blut eine Eindickung erfahre, infolge deren die erwähnten Werthe relativ normal erscheinen.

Diese Erklärung, und zwar ganz besonders das Moment des Schwitzens, wird denn auch von manchen Autoren, wie z. B. von Dehio ${ }^{2}$ ) als vollständig ausreichend angesehen, doch kann ich mich dem nicht anschliessen aus folgenden Gründen: erstens nämlich schwitzen Phthisiker nicht den ganzen Tag über, sondern nur zu gewissen Zeiten, zumeist im Anschluss an eine Temperatursteigerung, während sie die übrige Zeit des Tages hindurch durchaus normale Hautsecretion zeigen. Ich habe nun an anderer Stelle ${ }^{3}$ ) gezeigt, dass das Blut die Wasserverluste, welche es durch Schwitzen erleidet, in der Regel mit grosser Schnelligkeit wieder ausgleicht, d. h. durch Fliissigkeitsaufnahme aus den Geweben wieder zu seiner früheren Concentration zurückkehrt, so dass man z. B. bei Leuten, die einer fortgesetzten Schwitzcur unterworfen werden, keineswegs im Laufe der Zeit eine Eindickung des Blutes beobachtet. Auch die Phthisiker ersetzen ihren Wasserverlust nach nächtlichen Schweissen durch Aufnahme von Getränken.

Zweitens wird die erwähnte Erklärung vollständig dadurch widerlegt, dass sich die normale Blutbeschaffenheit auch bei solchen Phthisikern nachweisen lässt, die nicht im geringsten schwitzen und auch sonst keinerlei abnorme Secretionen aufweisen, ja mall kann sogar sagen, dass abnorm stark schwitzende Phthisiker infolge des meist dabei bestehenden hohen Fiebers immer eine Herabsetzung der Bestand theile des Blutes zeigen.

Die Erklärung dieses Verhaltens des Blutes bei vorgeschrittener Phthise ist meines Erachtens nach einer anderen Richtung hin zu suchen.

1) S. Laache, Die Anămie, 1883, p. 74.

2) Dehio, Petersburger med. Wochenschrift 1891 No. 1.

E Grawitz, Klin.experim. Blutunters. I. Zeitschrift f klin. Med. Bd. 21, H. 5 u. 6.
Zunächst ist es fraglos, dass eine Anämie bei den Phthisikern trotz dieser Blutbefunde besteht, denn abgesehen von der Blässe der Haut ergiebt jede Section eines Tuberkulosen derartige Blutarmuth der meisten Organe, dass eine Verminderung der Blutmenge und damit auch des normalen circulirenden Eiweiss- und Hämoglobingehaltes unzweifelhaft ist. Die erwähnten Blutbefunde zeigen eben nur die Verhältnisse in der Raumeinheit z. B. eines Cubikmillimeters an, und diese Werthe sind, da eine Bestimmung der Gesammtblutmenge nicht möglich ist, eben nur relative, so dass wir bei diesen Phthisikern eine Anämie in der Form einer Oligämie, d. h. eine Verminderung des Gesammtblutes bei annähernd normaler Zusammensetzung desselben vor uns haben. Es muss also hier ein Factor wirken, welcher die Eindickung des anämischen Blutes verursacht, und dass dieser nicht, oder nur in Ausnahmefällen in dem Bestehen profuser Secretionen zu suchen ist, habe ich schon gezeigt.

Dagegen muss ich hier daran erinnern, dass zuerst von G. Gärtner und F. Römer ${ }^{l}$ ) und später von mir $^{2}$ ) nachgewiesen ist, dass $d$ as Tuberkulin einen lymphtreibenden Einfluss im Blute ausübt, derart wie es Heidenhain in seiner bekannten Arbeit über Iymphtreibende Mittel vom Krebsmuskelextract $u$. a. gezeigt hat, dass nämlich durch das 'Tuberkulin ein Uebertritt von Flüssigkeit aus dem Blute in die Gewebe erfolgt.

Dieses Factum schien mir bei den Blutbefunden an Tuberkulösen auf eine Erklärung hinzuweisen, und ich habe deshalb versucht, ob auch die Producte des tuberkulösen Processes selbst eine derartige Wirkung ausübten. Zu diesem Zwecke habe ich von tuberkulösen Lungen käsig pneumonische Massen und käsige peribronchitische Knoten ausgeschnitten unter möglichster Vermeidung solcher Stellen, welche Eitererreger enthalten konnten, und habe nach gehöriger Zerkleinerung dieser Stücke Extracte nach der von Heidenhain angegebenen Methode derart dargestellt, dass die Stücke nach mehrmaligem Uebergiessen und Stehenlassen mit 97\% Alkohol getrocknet, gepulvert und mit etwa 10 Theilen Wasser gekocht wurden, worauf nach Filtration eine klare, gelbliche Flüssigkeit erhalten wurde. Diese Extracte habe icl in derselben Weise an Kaninchen auf ihre lymphtreibende Wirkung erprobt, wie ich es früher (Zeitsch. f. klin. Med. Bd. XXII, H. 4 und 5) ausfülırlich beschrieben habe, nur mit dem Unterschjede, dass ich nicht allein die Aenderungen des specifischen Gewichts des Blutes nach intravenöser Injection der Extracte beobachtete, sondern gleichzeitig noch die Aenderungen der Trockensubstanz des ganzen Blutes und des Serunus nach der oben erwähnten Methode ermittelte.

Ein Beispiel von fünf gleichartig verlaufenen Experimenten erläutert den Effect dieser Injectionen. Kräftiges 2 Kilo schweres Kaninchen zeigt:

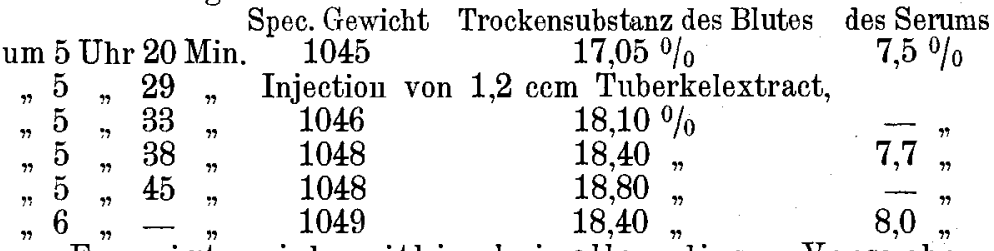

Es" zeigte sich mithin bei allen "diesen Versuchen, dass das Extract aus tuberkulösen Massen menschlicher Lungen eine deutliche bluteindickende Wirkung besitzt, infolge deren das specifische Gewicht des Blutes steigt, und die Trockensubstanz sowohl des ganzen Blutes, wie auch des Serums allein zunimınt. Aus diesem letzteren Umstande, nämlich der Eindickung des Serums ergiebt sich, dass die Flüssigkeit, welche infolge der Extractinjection das Blut verlässt und zur Eindickungdesselben führt, ärmer an festen Bestaudtlıeilen sein muss, als das Serum.

Diese Verhältnisse erklären meines Erachtens in der natürlichsten und einfachsten Weise die auffälligen Blutbefunde bei Kranken mit vorgeschrittener Lungenphthise, denn in diesem Stadium sind zumal bei ulcerösem Zerfall der tuberkulösen Producte in den Lungen die Bedingungen für die Resorption derselben besonders günstig, während im Beginne der Erkrankung dieser Einfluss auf das Blut fortfällt, und die Zeichen der Anämie daher auch im einzeInen Blutströpfchen deutlich ausgesprochen sind, wodurch sich in der natürlichsten Weise das paradoxe Verbältniss erklärt, dass mit dem Zunehmen der Erkrankung und der Zeichen der Anämie die Concentration des Blutes sich mehr dem Normalen nähert.

Ein ganz anderer Factor tritt nun ein, wenn sich zu der Tuberkulose die sogenannten hektischen Fieber gesellen, welche klinisch grosse Aehnlichkeit mit Fieberanfällen bei Eiterungen zeigen und von bacteriologischer Seite ${ }^{3}$ ) auch als Folge der Ansiedelung von Eiterbacterien in den ulcerösen Lungen angesehen werden.

1) Wien. klin. Wochenschr. 1892 No. 2.

2) Zeitschr. f. klin. Med. Bd. 22, H. 4 u. 5.

3) Petruschky, Tuberculose und Septicämie. Deutsche medicin. Wochenschr. 1893 No. 14. 
Die häufig ganz erhebliche Herabsetzung der festen Bestandtheile des Blutes und der Zahl der rothen Blutkörperchen bei Kranken in diesem Stadium ist als Einwirkung septischer Stoffe a uf das Blut aufzufassen, welche gerade eine entgegengesetzte Wirkung ausüben, wie die Tuberkelextracte. Nachdem ich nämlich bereits früher im Thierexperiment gefunden, dass Culturen von eitererregenden Coccen eine blutverdünnende Wirkung ausüben, habe ich auch an Menschen durch eine grössere Zahl exacter Blutanalysen bei septischen Infectionen, besonders Puerperalfiebern, ausnahmslos so starke Verdünnungen des Blutes gefunden, wie sie z. B. bei Typhen oder Pneumonieen nur in Ausnahmefällen zu beobachten sind. Diese Verdünnungen des Blutes bei Sepsis beruhen nun ohne Zweifel zum Theil auf einem Zugrundegehen von rothen Blutkörperchen, wie ich noch jüngst in einem Falle acutester puerperaler Sepsis beobachten konnte, wo sich im Urin massenhaft Hämoglobin und ebenso im frisch abgesetzten Serum des Blutes erhebliche Mengen von Hämoglobin nachweisen liessen, ferner aber anch auf einer lymphtreibenden Wirkung der septischen Stoffe, welche eine blutverdünnende Wirkung ausüben, wie es die Versuche am Thier bewiesen haben.

Es sind also entgegengesetzte Wirkungen, welche die Producte der tuberkulösen und septischen Processe auf die Säfteströmung im Organismus des kranken Menschen ausüben, und es scheint, als ob die septischen Stoffe in der Stärke der Wirksamkeit bei weitem prävaliren.

\section{B. Blut bei Krebskranken.}

Erheblich einfacher liegen die Blutverhältnisse bei Krebskranken; icl kann mich hierüber um so kürzer fassen, als meine Blutbefunde in ihren Resultaten hier durchaus mit denen übereinstimmen, welche von früheren Untersuchern, wie Laker, Leichtenstern, La ache, Fr. Müller, v. Noorden u. a. gefunden sind und welche dahin gehen, dass die Zahlen der rothen Blutkörperchen, und proportional die Trockensubstanz des Blutes, ebenso das specifische Gewicht desselben und gleichzeitig auch die Trockensubstanz des Serums eine Herabminderung erfahren, mit dem Vorschreiten der Krebskachexie weiterhin heruntergehen und unter Umständen ganz extrem niedrige Werthe erreichen können. Auf die Verhältnisse der weissen Blutkörperchen, welche unter gewissen Umständen eine Vermehrung erfahren, will ich hier nicht näher eingehen, ebenso erwähne ich nur kurz, dass die rothen Blutkörperchen bei schweren Anämieen Carcinomatöser häufig morphologische Veränderungen wie bei anderen schweren Anämieen erfahren und als Mikro-, Makro- und Poikilocyten erscheinen.

Als Beispiel führe ich von meinen Beobachtungen Frau D. an, eine magere, blasse Frau mit Carcinom des Oesophagus, mässiger Strictur desselben bei relativ guter Nahrungsaufnahme. Das Venenblut zeigte 3,0 Millionen rothe Blutkörperchen, Trockensubstanz des Blutes $18,50 \%$, Trockensubstanz des Serums $8,96 \%$, specifisches Gewicht 1046,1.

Dieselbe Patientin, 4 Wochen später untersucht, nachdem das Körpergewicht 4 Pfund abgenommen hatte, zeigte 2,5 Millionen rothe Blutkörperchen, Trockensubstanz des Blutes 17,98\%, Trockensubstanz des Serums 7,45 \% , specifisches Gewicht 1040.

Auffällig ist es auch bei Krebskranken, dass besonders gegen das Ende des Lebens hin unter gewissen Umständen normale, oder sogar übernormale Werthe für die rothen Blutkörperchen und festen Bestandtheile gefunden werden, während gleichzeitig die äusseren Zeichen der Anämie in stärkster Weise ausgeprägt sind. Dass diese letzteren Verhältnisse durch eine Eindickung des Blutes infolge hochgradiger Wasserverarmung der Gewebe bei Oesophagusund Magencarcinom mit erheblicher Beschränkung der Resorption bedingt sind, ist bereits durch meinen Collegen v. Noorden (l. c.) in eingehender Weise auseinandergesetzt worden.

Wenn ich nun von diesen letztgenannten Verhältnissen absehe, so ist die starke Verdünnung des Blutes, welche bei einfacher Krebskachexie so regelmässig und ausgesprochen zu constatiren ist, besonders im Hinblick auf die so gänzlich verschiedenen Verhältnisse bei der Kachexie der Schwindsüchtigen immerhin auffallend, und es wird auf Grund zahlreicher Stoffwechseluntersuchungen, und zwar in erster Linie derer von Fr. Müllerl) angenommen, dass in den Säften der Krebskranken toxische Stoffe kreisen, welche einen Zerfall des Protoplasma, und somit auch Verarmung des Blutes an festen Bestandtheilen bewirken.

Ausser diesem Moment des protoplasmazerstörenden Einflusses auf die Concentration des Blutes glaube ich aber nach gewissen Versuchen darauf aufmerksam machen zu müssen, dass auch bei Krebskranken anscheinend Lymphströmungen rom Blute her hervorgerufen werden, welche zu einer Anziehung von

1) Fr. Muller, Stoffwechseluntersuchung bei Krebskranken. Zeitschr. klin. Med, Bd, 16 ,
Flüssigkeit in dasselbe, und somit zur Verdünnung führen, resp. mit beitragen.

Die Versuche, welche für diese Annahme sprechen, habe ich in derselben. Weise angeordnet wie die vorher erwähnten, mit Tuberkelextract ausgeführten. Ich habe krebsige Wucherungen, und zwar vorwiegend frisch exstirpirte Uteruscarcinome, welche mir durch die Güte meines Collegen, des Herrn Stabsarzt Dr O. Müller, von der gynäkologischen Abtheilung des Herrn Geheimrath Gusserow unmittelbar nach der Operation überwiesen wurden, unter sorgfältiger Vermeidung normalen Gewebes ausgeschnitten, in der erwähnten Weise zerkleinert, mit Alkolool behandelt, getrocknet, gepulvert und durch Kochen im Wasserbade extrahirt Das filtrirte, klare, gelbliche Extract wurde auf seine lymphtreibende Wirkung in derselben Weise, wie oben erwähnt, bei 6 Kaninchen erprobt und gab eine Einwirkung auf die Blutmischung, welche das folgende mittelwerthige Beispiel erläutert.

Sehr kräftiges Kaninchen, 2,5 Kilo schwer zeigt:

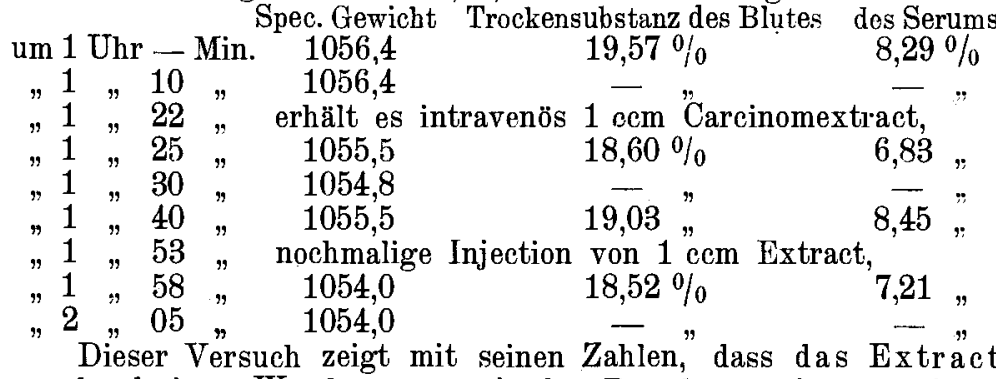
aus krebsigen Wucherungen in der Blutbahn eine ähnliche lymphtreibende Wirkung äussert wie z. B. Salze und Zucker, nämlich eine Flüssigkeit anziehende und blutverdünnende, mithin eine dem Tuberkelextract entgegengesetzte. Dass eine Auflösung rother Blutkörperchen bei diesen Injectionen keine Rolle gespielt hat, war daran zu ersehen, dass sich in dem klar abgesetzten Serum des Blutes nach Einführung des Extracts Hämoglobin, auch in kleinsten Spuren, spectroskopisclı nicht nachweisen liess.

Auch die starke Erniedrigung der Trockenrückstände des Serums nach der Injection spricht gegen den Uebertritt gelösten Hämoglobins in dasselbe, und gleichzeitig beweist dieselbe, dass eine Flüssigkeit von geringerem Trockengehalt als Serum in das Blut übergetreten ist und die Verdünnung bewirkt hat, umgekehrt wie nach der Injection der Tuberkelextracte.

Die im Vorstehenden geschilderten Blutuntersuchungen und Experimente lehnen sich an früher von mir mitgetheilte Beobachtungen über Säfteströmungen im Organismus an und liefern einen kleinen Beitrag erstens zur Methodik derartiger Untersuchungen, die eine sehr subtile Berücksichtigung vielfacher technischer Fragen erheischt, zweitens zur Kenntniss dieser Säfteströmungen bei zwei unserer häufigsten und wichtigsten Krankheiten und des Einflusses, den dieselben auf die Beschaffenheit des Blutes ausüben. Inbezug auf das Blut selbst zeigen sie, dass Resultate einzelner Blutuntersuchungen am Menschen nur mit Vorsicht gedeutet werden dürfen, da diese Resultate nur die sehr variable Beschaffenheit eines einzelnen Blutströpfchens anzeigen, über das Verhalten des Gesammtblutes aber keinen Aufschluss geben. 